\title{
Effect of positive ionisation of inspired air on the response of asthmatic children to exercise
}

\author{
I LIPIN, I GUR, Y AMITAI, I AMIRAV, S GODFREY \\ From the Pulmonary Function Laboratory and Department of Pediatrics, Hadassah University Hospital, \\ Jerusalem, Israel
}

\begin{abstract}
To evaluate the effect of positive ionisation of inspired air on bronchial reactivity, 12 asthmatic children were twice challenged by exercise in random order. During one test positively ionised air (5-10 $\times 10^{5}$ ions $\left./ \mathrm{cm}\right)$ was breathed. All challenges were matched in terms of basal lung function and exercise tests were matched in terms of ventilation and respiratory heat loss. Exercise induced asthma was significantly aggravated by exposure to positively ionised air, the postexercise fall in $\mathrm{FEV}_{1}\left(\triangle \mathrm{FEV}_{1}\right)$ being $24.7 \%$ (SEM and $\left.5.3 \%\right)$ and $35.3 \%(5 \%)$ after the control and ionised air tests respectively $(p<0.04)$. It is concluded that positive ionisation aggravates the bronchial response to exercise.
\end{abstract}

Asthmatic subjects are characterised by increased airway reactivity when exposed to various stimuli, both specific ones such as antigen inhalation and non-specific ones such as physical exertion. ${ }^{2}$

The ionic charge of the air has for long been thought to affect various biological systems, ${ }^{34}$ including the respiratory system, which is highly exposed to air constituents. ${ }^{56}$ Uncontrolled studies in the past have suggested a beneficial effect of negative ions on lung function in asthmatics but the observed changes were always minor. ${ }^{78}$ Recently we studied the effect of negative ionisation of inspired air on the response of asthmatic children to exercise and inhaled histamine. ${ }^{9}$ We found that negative ionisation significantly attenuated the response to exercise but the effect on histamine responsiveness was more variable. To investigate this further we decided to study the response of asthmatic children to exercise while they were breathing positively ionised air under similarly controlled conditions.

\section{Methods}

Twelve asthmatic children, seven of them boys, with a mean age of 12 (range 9-15) years participated in this study. All were known to have had asthmatic attacks provoked by physical exertion. Children and

Address for reprint requests: Dr S Godfrey, Department of Pediatrics, Hadassah University Hospital, Mount Scopus, POB 24035, Jerusalem 91240, Israel.

Accepted 13 March 1984 parents gave informed consent to the tests after a full explanation of the procedure. The child refrained from taking sympathomimetic medication or sodium cromoglycate for at least 12 hours and long acting theophylline for 24 hours before any test. Inhaled steroids, if taken, were continued at the same dose level throughout the study. Regular medication was by means of sympathomimetic bronchodilators in seven patients, sodium cromoglycate in one, long acting theophylline in one, and beclomethasone dipropionate in three. Exercise tests were undertaken with and without exposure to positively charged inspired air in a double blind randomised fashion, with the same protocol as in our previous study of negative ions but reversing the polarity of the ion generator. ${ }^{9}$ The ion generator was silent in action and was turned on or left off by a staff member not concerned with the project and without the knowledge of the child or the investigators. The subjects breathed cold, dry air with or without the addition of positively charged ions for 10 minutes before exercise and throughout the exercise and subsequent recovery. Ions were produced by a generator (Modulion System, Amcor, Israel), which was connected to the inspired air line close to the mouth. Ion concentration measured at the mouthpiece (Kathrein Ionometer MGK 01) for each individual was 5-10 $\times 10^{5}$ ions $/ \mathrm{cm}$ during the exercise tests.

Expired air was directed to a mixing chamber and pneumotachygraph coupled with a gas analyser (PK Morgan, Exercise Test System, England), which 594 
enable ventilation and gas exchange to be continuously recorded during the exercise tests. Lung function was measured with a pneumotachygraph based calculator system (Vanguard DS 500, Massachusetts, USA) connected to the expiratory side of the circuit in such a way as to enable the child to breathe the test gas throughout, even during lung function testing.

The subjects undertook two identical six minute exercise tests 24 hours apart, using a cycle ergometer (Lode Instruments). Work load was calculated to achieve about two thirds of the maximal predicted oxygen consumption for each individual. When measured at the mouthpiece the inspired air had a temperature of $9.8^{\circ}\left(\mathrm{SD} 0.5^{\circ}\right) \mathrm{C}$ and water content $3.8(0.4) \mathrm{mg} \mathrm{H}_{2} \mathrm{O} / \mathrm{l}$. Respiratory heat loss was calculated as described by Deal et al. $^{10}$

Lung function was assessed at the start of a test day, after five minutes of breathing the cold test gas and after 10 minutes of exposure either to the ionised air or to the control non-ionised air just before the start of the cycling. Measurements were then made three, 10, and 20 minutes after the exercise test. The greatest forced expired volume in one second $\left(\mathrm{FEV}_{1}\right)$ of two or three attempts was recorded. The test gas was continuously breathed and measurements were continued until the $\mathrm{FEV}_{1}$ returned to $90 \%$ of the pre-exercise value.

Bronchoconstriction after exercise was expressed as the maximum percentage fall in $\mathrm{FEV}_{1}\left(\triangle F E V_{1}\right)$ from the baseline value recorded after 10 minutes of exposure to the ionised or non-ionised cold dry gas just before the cycling. Differences were analysed by means of the paired $t$ test and were considered significant if $\mathrm{p}$ was less than $0 \cdot 05$.

Individual values of baseline $F E V_{1}$ and postexercise fall in $F E V_{1}\left(\triangle F E V_{1}\right)$ in the control and ionised air exercise tests

\begin{tabular}{llllll}
\hline $\begin{array}{lllll}\text { Subject } \\
\text { No }\end{array}$ & \multicolumn{3}{l}{ Control } & \multicolumn{2}{l}{ Ionisation } \\
\cline { 2 - 3 } \cline { 5 - 6 } & $\begin{array}{c}\text { Baseline } \\
F E V_{1}(1)\end{array}$ & $\begin{array}{c}\Delta F E V_{1} \\
(\%)\end{array}$ & & $\begin{array}{l}\text { Baseline } \\
F E V_{1}(1)\end{array}$ & $\begin{array}{l}\Delta F E V_{1} \\
(\%)\end{array}$ \\
\hline 1 & 2.56 & 38 & 2.56 & 48 \\
2 & 1.98 & 37 & 1.98 & 38 \\
3 & 1.29 & 5 & 1.20 & 15 \\
4 & 1.90 & 6 & 1.90 & 18 \\
5 & 1.71 & 7 & 1.60 & 16 \\
6 & 2.16 & 38 & 2.16 & 49 \\
7 & 1.61 & 6 & 1.55 & 63 \\
8 & 1.78 & 42 & 1.70 & 25 \\
9 & 1.16 & 60 & 1.21 & 60 \\
10 & 1.01 & 21 & 1.11 & 31 \\
11 & 1.37 & 26 & 1.24 & 17 \\
12 & 1.40 & 10 & 1.48 & 44 \\
Mean & 1.66 & 25 & 1.64 & 35 \\
SEM & 0.12 & 5 & 0.12 & 5 \\
\hline
\end{tabular}

Results

The exercise tests for the individual patients were closely matched and paired $t$ tests showed no significant differences between the control and ionisation tests in terms of minute ventilation (38.4 (SEM 3.1) and $38.9(3.2) 1 / \mathrm{min}$ ), oxygen consumption (34.5 (1.8) and $35.2(2.0) \mathrm{ml} / \mathrm{kg} / \mathrm{min})$, heart rate (149 (4) and 150 (4) beats/min), and respiratory heat loss $(0.60(0.05)$ and $0.62(0.06) \mathrm{kcal} / \mathrm{min}$ $(1 \mathrm{~kJ}=0.239 \mathrm{kcal}))$. There was also no significant difference between the control and ionised baseline FEV $_{1}$ values $(1.66(0.12)$ and $1.64(0.12)$ l). Individual values for the baseline $F E V_{1}$ and for the $\triangle F E V_{1}$ following the exercise tests are presented in the table. The postexercise fall in $\mathrm{FEV}_{1}$ was significantly greater during the breathing of positively ionised air than during the control test $(p=0.04)$. Eight subjects developed more exercise induced asthma and two subjects less, and two showed no difference.

\section{Discussion}

The results show that positively ionised air aggravated exercise induced asthma in eight out of 12 subjects tested. The concentration of positive ions was of the same order as the negative ions in our previous study, in which we found attenuation of exercise induced asthma.9 The concentration of positive ions in the mouthpiece, however, was about 100 times that occurring naturally in the 24 hours before a "hamsin," the sharp increase in air temperature and decrease in air humidity which occurs in the Middle East. " Clinical experience suggests that asthma is more troublesome at these times. The high concentration of positive ions in the present study had no effect on basal lung function.

Five of the children in the present study had also taken part in the previous study of the effect of negative ions some six months earlier.' All five developed less asthma with negative ions than in the control test on the same day. In the present study three developed more asthma, one the same amount, and one less asthma with positive ions than in the control test. There was considerable individual variation in the control tests between the two studies and therefore a formal analysis comparing the results is not possible.

In conclusion, the ionic charge of the air can influence the bronchial response to exercise and this, in addition to temperature and humidity, could be a modifying factor. There is at present no definite evidence on the mechanism by which ions influence exercise induced asthma. 


\section{References}

' Godfrey S. Stimuli to bronchoconstriction: basic mechanisms. Isr J Med Sci 1982;18:297-306.

${ }^{2}$ Bushey HA, Holtzman MJ, Sheller JR, Nadel JA. Bronchial hyperreactivity. Am Rev Resp Disir 1980;121:389-413.

${ }^{3}$ Krueger AP, Reed EJ. Biological impact of small air ions. Science 1976;193:1209-13.

${ }^{4}$ Winsor T, Becket JC. Biological effects of ionized air in man. Am J Phys Med 1958;37:83-9.

5 Badre R, Guillern R, Hee J. Study in vitro of the action of light atmospheric ions on the ciliary activity of the tracheal epithelium. Ann Pharm Fr 1966;24:469-78.

${ }^{6}$ Palti Y, De Nour E, Abrahamov A. The effects of atmospheric ions on the respiratory systems of infants. Pediatrics 1966;38:405-11.
7 Jones DP, O'Connor SA, Collins JV, Watson BW. Effects of long term ionized air treatment on patients with bronchial asthma. Thorax 1976;31:428-32.

${ }^{8}$ Osterballe $\mathrm{O}$, Weeke $\mathrm{B}$, Albrechtsen $\mathrm{O}$. Influence of small atmospheric ions on airways in patients with bronchial asthma. Allergy 1979;34:187-94.

${ }^{9}$ Ben-Dov I, Amirav I, Schochina M, Amitai I, BarYishay E, Godfrey S. The effect of negative ionization of inspired air on the response of asthmatic children to exercise and inhaled histamine. Thorax 1983;38:584-8.

${ }^{10}$ Deal EC, McFadden ER, Ingram RH, Jaeger JJ. Role of respiratory heat exchange in production of exercise induced asthma. J Appl Physiol 1979;46:467-75.

"Robinson V, Direnfeld JS. The ionization state of the atmosphere as a function of the meteorological elements and various sources of ions. Int J Biometeorol 1963;6:101-10. 